\title{
Analysis and optimizing the performance of photovoltaic power systems under partial shading condition
}

\author{
تحليل وتعظيم الأداء لتظم القوى القوتوقولتية تحث تأثير الظل الجزئي
}

\author{
S.S.Kaddah, EL-H.Abd-Raboh, K.M.Abo-EL-EZ and S.A.Diab
}

Faculty of Engineering, Mansoura University, Department of Electrical Engineering.

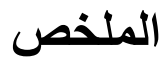

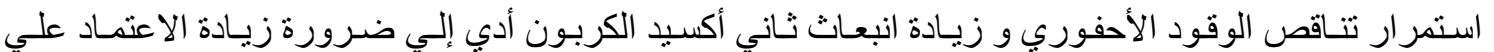

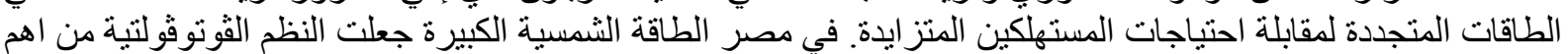

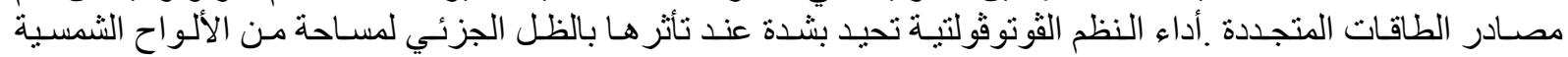

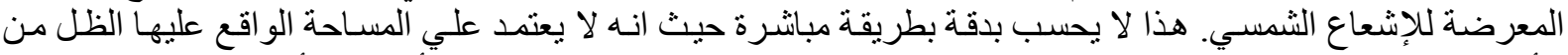

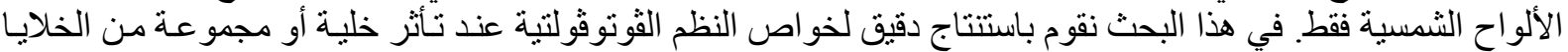

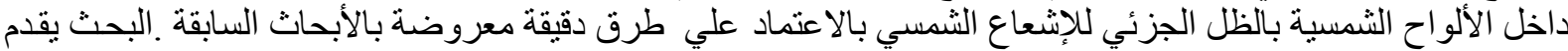

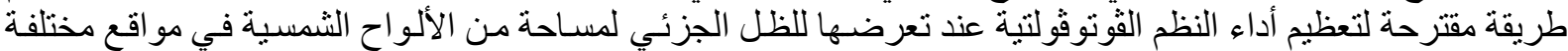

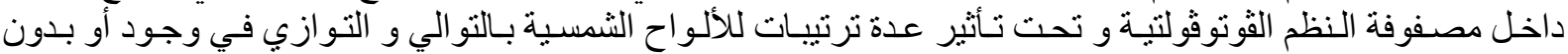

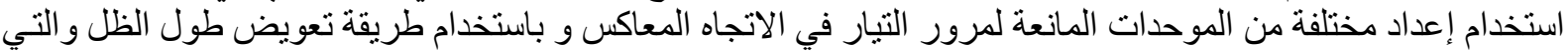

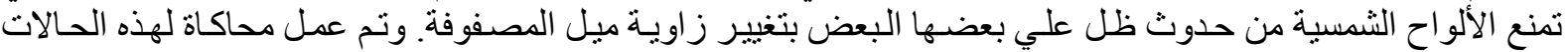

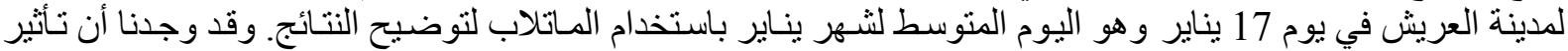

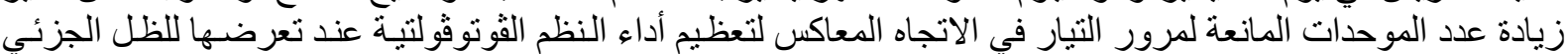

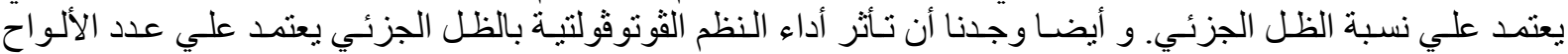

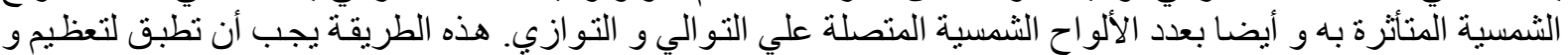

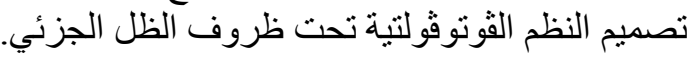

\section{Abstract}

Growing shortage of fossil fuels and increasing emissions of $\mathrm{CO} 2$ make it a must to increase relying to the renewable energies for meeting the growing needs of consumers. In Egypt, the availability of solar energy put photovoltaic (PV) systems among the most important of these energies. The performance of Photovoltaic (PV) systems is deviated severely under partial shading condition (PSC). And this deviation is not determined in straight forward way, since it is not depending on the shaded area only. In this paper we have been present a simple methodology to evaluate accurately the characteristics (c/cs) of large and small scales of PV systems when one cell or group of cells in different sub-modules are partially shaded based on well-established algorithms. We enlarge this methodology to analysis then optimize the performance of PV arrays under PSC in different criteria for different series-parallel configurations of modules inside the array, with and without different numbers of bypass diodes $\left(D_{b y}\right)$ and using the shadow length compensation algorithm which prevents the mutual shading between arrays through adjusting the tilt angle. A Matlab simulation is done to verify the theoretical analysis for Al-Arish at 17th January which is the average day in January. We found that the impact of increasing the number of Dby to optimize the performance of PV systems under PSC depends on the shading ratios. Also we found that the harmful impact of PSC on PV systems depend on the number of sub-modules under PSC, the length of strings and number of strings connected in parallel. This methodology should be applied for optimizing and sizing PV systems which are partially shaded. 


\section{Introduction}

Both political and environmental trends go for renewable energy as promising power resources. The PV systems are quiet, free of moving parts and need low maintenance and operation costs. This makes them to be usable on large scales in both standalone and grid connected applications. But these PV systems are dependent energy sources which are affected badly by surrounding environmental and ambient conditions of operation. One of the most detrimental factors on performance of PV is partially shading in modules or arrays.

For Most applications, PV modules are connected in series / parallel to get the desired system voltage and current. When modules or cells partially damaged, short circuit fault may occur due to this damage. If cells in these modules do not have identical characteristics due to partial shading fault or short circuit fault, there will be difference between the maximum output power available from the module or array and the sum of the maximum output powers for each of the cells or modules, which is referred as the "mismatch losses"[1-2].

Despite the valuable researches in modeling and simulation of PV systems [34] under temperature and irradiance, there is a great need to model and simulate the PV systems at ambient affecting factors which deviate their performance. PSC can occur due to hard shading from tree leaves falling over cells, birds or bird litters on cells or soft shading due to neighboring buildings or arrays or passing clouds.

If these losses are not taken into account, the power output of PV system is often severely lower than expected and the performance of the PV will not be predicted accurately. So designers of PV systems should consider these losses to optimize their designs and size of PV systems. The deviation in performance caused by PSC is non-linear and varies according to the configuration of cells inside modules, modules inside the array and configuration of Dby across arrays. When PSC occur in modules or arrays, there will be consequences:

1-the irradiance received by the shaded area will be reduced than that received by the fully illuminated area(FI) and this will cause the shaded area to pass currents higher than their short circuit current $\left(\mathrm{I}_{\mathrm{SC}}\right)$ and operate at reverse bias, so this area in module will consume power rather than generating it.

2- The excessive reverse bias due to high shading ratios will cause damage to the cells themselves [5].

3-And since arrays partially shaded have several peaks in its $\mathrm{P}-\mathrm{V}$ characteristics curve, the traditionally tracking methods will fail to track maximum output power [6]-[7].

There are several approaches to shading analysis and losses as in [8]-[11]. But a detailed and accurate prediction of the performance of PV systems on large and small scales under PSC considering different configurations of modules inside the array, increasing the integration of $D_{b y}$ across each module, the number of submodules under PSC and the influence of different shading ratios on the effectiveness of these solutions is not reported despite being of high importance for optimum designing and sizing of PV systems.

Methods to minimize shading losses are as following:

1-Shading harmful effect on the power output of PV modules can be minimized by a recommended spacing between rows of modules at different latitudes ,different orientations, and different cells sizes to reduce mutual shading between modules [12]. Or installing PV systems on large area to prevent shading from arrays itself and ambient instruments on other but this will cause increasing the installation price [13].

2-In [14]-[15] the implementation of bypass $\operatorname{diodes}\left(D_{b y}\right)$ on the module and array scale is introduced and it was found that by increasing number of these diodes 
the power losses due to shading theoretically reduces but this in real is not happening since there are losses in these diodes also they increase the system nonlinearity.

3-Another solution to reduce losses from shading was proposed in [1], [16]by dynamically reconfigure the cells inside module according to the levels of irradiance experienced by the individual cells. It is found through simulation results that the power from a partially shaded module can be typically doubled by the use of this technique. In this proposed method, the effect of local shadows was canceled by paralleling cells subjected to shading with those that are not shaded by connecting the fully illuminated cells in one series circuit. To implement this method modules considered in study will be number of sub-modules connected in series instead of the industry standard modules. Each sub-module may be composed of various series - parallel combinations.

4-In [13], an Algorithm for compensation of shadow was presented to avoid the occurrence of shadowing of arrays on each other by adjusting the inclination of the arrays. Through this algorithm shadow length and distance between arrays were calculated.

The main contribution of this paper is to present a methodology which analysis and evaluate the losses due to PSC occurred in different criteria in PV systems in which modules are connected in different configurations and integrated with different numbers of Dby . Based on this methodology, we can optimize the performance of any PV system under PSC by selecting the optimum configuration of PV modules inside the array and the optimum number of Dby to be integrated across each module based on whether the shading occurred due to passing clouds or due to modules on each other. Also a comparison between impact of implementing Dby and implementing the shadow length compensation algorithm
(SLCA) which prevent mutual shading between arrays.

\section{Effect of partial shading on PV performance}

If PV module is partially shaded, power will be reduced due to two reasons. Firstly because of decreasing the area of PV array receiving irradiance. Secondly, since the current passing through the series cells inside the module should be constant, the cells under PSC are forced to pass current higher than their short circuit current and this will make them operate at reverse bias and will consume power and act as a load [16]. If an excessive reverse bias voltage occurs when the difference in irradiance levels is extremely high due to high shading ratios, the internal diode $\mathrm{D}$ in Fig.1 offers high resistance creating an open circuit in the entire PV module and there will be over heating causing hot spot point which can damage the diode itself [5].

When the irradiance received by the PV module $G$ is composed of direct or beam $H_{B}$, diffuse $H_{D}$ and reflected $H_{R}$ components. And when the diffuse component composed of isotropic $\mathrm{H}_{\mathrm{D}}{ }^{\text {ISO }}$ and circumsolar $\mathrm{H}_{\mathrm{D}}{ }^{\mathrm{CIR}}$ and horizon $\mathrm{H}_{\mathrm{D}}{ }^{\mathrm{HZ}}$ components, the effective shading ratios applied only to the direct component and circumsolar part of diffuse [12],[17].

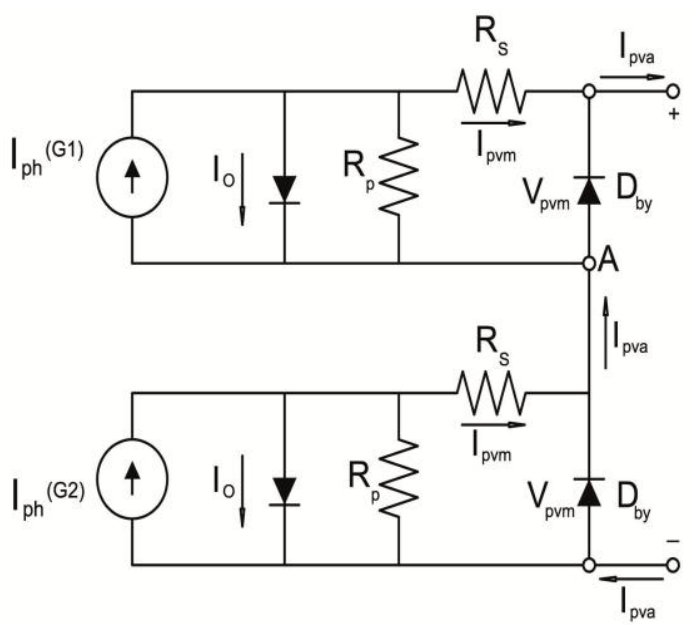

Fig.1 Equivalent circuit of PV module partially shaded. 
The irradiance $\mathrm{G}_{\mathrm{sh}}$ received by cells which are shaded by shading ratio of $S_{h}\left(S_{h}\right.$ referring to the percentage area of the cell which is shaded) can be calculated from equation.1[8],[11],[12].

$$
\mathrm{G}_{\mathrm{sh}}=\left(\mathrm{HD}^{\mathrm{CIR}}+\mathrm{HB}\right)\left(1-\mathrm{S}_{\mathrm{h}}\right)+\mathrm{HD}^{\mathrm{ISO}}
$$$$
+\mathrm{HD}^{\mathrm{hz}}+\mathrm{HR} \text {. }
$$

At 17 January in Al Arish city, we will study the shading effect when one cell in a module of BPMSX-150 W type is shaded with different shading ratios. The shading factor $\mathrm{F}$ calculated from equation.2 [1], [11], [17], and it can be used to estimate $\mathrm{I}_{\mathrm{SC}}$ under PSC.

$$
F=\frac{\mathrm{Gsh}}{\mathrm{G}}=\frac{\mathrm{Isc}, \mathrm{sh}}{\mathrm{Isc}}
$$

To reduce the effect of PSC and prevent damage of cells due to reverse bias, different numbers of bypass diodes are integrated across the module. Bypass diodes divide the module into several submodules each is protected by one bypass diode.

Shading losses can be characterized by two important parameters, the irradiance value after shading which depends on the shading factor, and the area blocked due to shading which depends on different numbers of $D_{b y}$ connected across each module. When considering the array scale, different configurations of series and parallel connections between modules will be the third parameter which affects the losses due shading. As more of the module gets shaded, the system may also show multiple power point maxima, making identification of the real one difficult for traditional trackers and potentially lead to oscillations about MPP or other undesirable behavior as illustrated in Fig. 2 $a$ and $b[3]$.

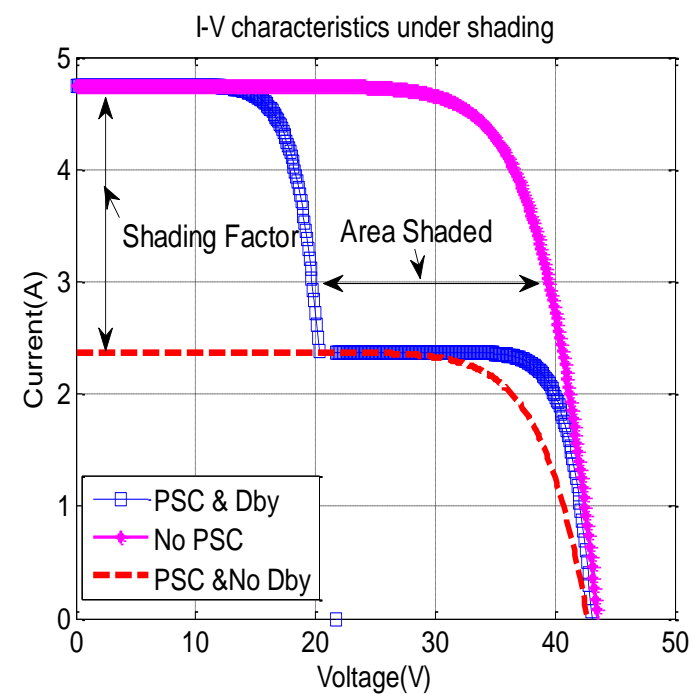

[a]

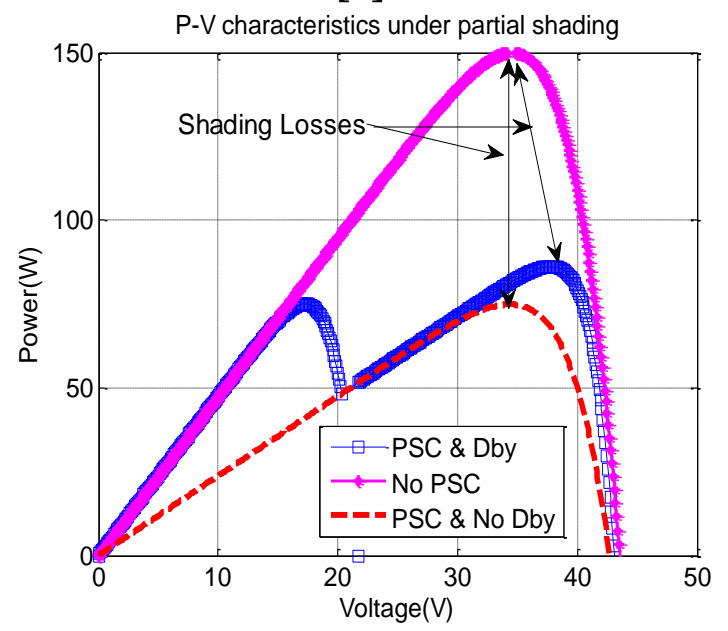

[b]

Fig.2 (a) I-V and (b) P-V c/cs of PV module under PSC.

Suggested solutions to reduce effect of shading on performance of PV systems are:

1. Integrating bypass diodes across each module

2. Different configurations of modules inside PV array

3. Implementing SLCA method.

\section{Integrating bypass diodes across each module at different shading ratios}

The performance of PV module under PSC at different shading ratios and different numbers of $D_{b y}$ is presented in the following sections. 


\subsection{One module with one Bypass diode}

If one cell in a module without bypass diode is shaded with different shading ratios $\mathrm{S}_{\mathrm{h}}$ in other words if different percentage areas $(25 \%, 50 \%, 75 \%, 100 \%)$ of one cell is shaded by shadow of clouds it will produce $\mathrm{I}_{\text {sh }}$ and voltage across it $\mathrm{V}_{\mathrm{sh}}$ and the rest of cells in the module are fully illuminated and produce $\mathrm{I}_{\mathrm{i}}$ and voltage across them $\mathrm{V}_{\mathrm{i}}$ .The output current $I_{M}$ and voltage $V_{M}$ of the module under PSC and only one bypass diode will equal the following mathematical model in equation.3[1]-[2] ,[14]:

$\mathrm{I}_{\mathrm{M}}=\operatorname{Min}\left(\mathrm{I}_{\mathrm{i}}, \mathrm{I}_{\mathrm{sh}}\right)$,

$\mathrm{V}_{\mathrm{M}}=\sum\left(\mathrm{V}_{\mathrm{sh}}, \mathrm{V}_{\mathrm{i}}\right)$

When applying equation. 3 to the day, site and module under study the values of $G$ $, \mathrm{I}_{\mathrm{sc}}, \mathrm{P}_{\max }$ and power reduction at noon under different values of $S_{h}$ are simulated and given in Table. 1

Table.1 performance of $P V$ module at noon under $P S C \&$ one $D_{b y}$.

\begin{tabular}{|c|c|c|c|c|c|}
\hline Sh (\%) & 0 & 25 & 50 & 75 & 100 \\
\hline F( \%) & 100 & 78.529 & 57.06 & 35.589 & 14.1197 \\
\hline G w/m2 & 758.69 & 595.80 & 432.9 & 270.02 & 107.124 \\
\hline $\begin{array}{c}\text { Isc } \\
(A)\end{array}$ & 3.6038 & 2.8301 & 2.056 & 1.2826 & 0.5088 \\
\hline Pmax (W) & 113.7 & 89.5 & 64.8 & 40.395 & 16.0156 \\
\hline $\begin{array}{c}\text { Power } \\
\text { reduction } \\
\%\end{array}$ & 0 & 21.523 & 43.02 & 64.482 & 85.9183 \\
\hline
\end{tabular}

On the module scale, 1 bypass diode, for shading ratios of $25 \%, 50 \%, 75 \%$ of one cell a reduction in the effective irradiant area by about $0.35 \%, 0.69 \%, 1.04 \%$, the performance of the shaded PV module is reduced by $21.5 \%, 43.02 \%, 64.5 \%$ respectively .

\subsection{One Module With Two Bypass Diode}

For one cell in a module partially shaded by $75 \%$ and connected with two bypass diodes. The current pass through module will be as shown in Fig. $3 \mathrm{a}$ and $\mathrm{b}$ [1],[14].

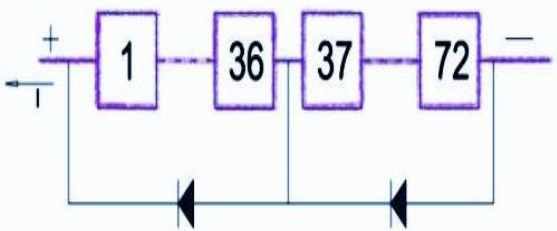

[a]

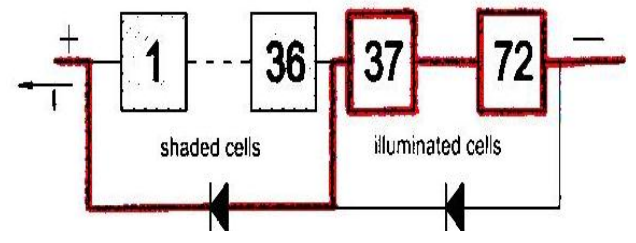

[b]

Fig. 3 the current pass in PV module under (a) fully illuminated and (b) PSC.

The bypass diode begins to conduct when equation 4 is satisfied:

$$
\mathrm{I}_{\mathrm{sh}}>\mathrm{I}_{\mathrm{i}}
$$

These diodes can be mathematically modeled as a high resistance $\left(10^{10} \Omega\right)$ when it is reverse biased and low resistance $\left(10^{-2} \Omega\right)$ when it is forward biased.

It can be concluded that characteristics of one module under PSC with two bypass diodes as following [1], [14]:

First zone

In which $\mathrm{I}_{\mathrm{sh}}<\mathrm{I}_{\mathrm{i}}$, so the cell under PSC will be reverse biased and the bypass diode will be forward bias and prevent the shaded cell from absorbing power by blocking the sub-module containing it. And the fully illuminated sub-module is producing the characteristics of the module under PSC in this zone.

$$
\mathrm{I}_{\mathrm{M}}=\mathrm{I}_{\mathrm{i}}, \quad \mathrm{V}_{\mathrm{M}}=\mathrm{V}_{\mathrm{i}}
$$

Second zone

Starts from point $\mathrm{P}$ as shown in Fig.4 at which $\mathrm{I}_{\mathrm{sh}}>\mathrm{I}_{\mathrm{i}}$, so the cell under PSC will be forward biased and the bypass diode will be reverse biased and the blocked sub-module is inserted to give the desired voltage of the module under PSC but at the level of current of the $\mathrm{I}_{\mathrm{sh}}$.

$\mathrm{I}_{\mathrm{M}}=\mathrm{I}_{\mathrm{sh}}, \quad \mathrm{V}_{\mathrm{M}}=\mathrm{V}_{\mathrm{i}}+\mathrm{V}_{\mathrm{sh}}$

The I-V and P-V c/cs of PV module in which one cell under PSC of $75 \%$ and 2 
Dby are connected are simulated based on equations 4-6 and results are drawn in Fig.4.

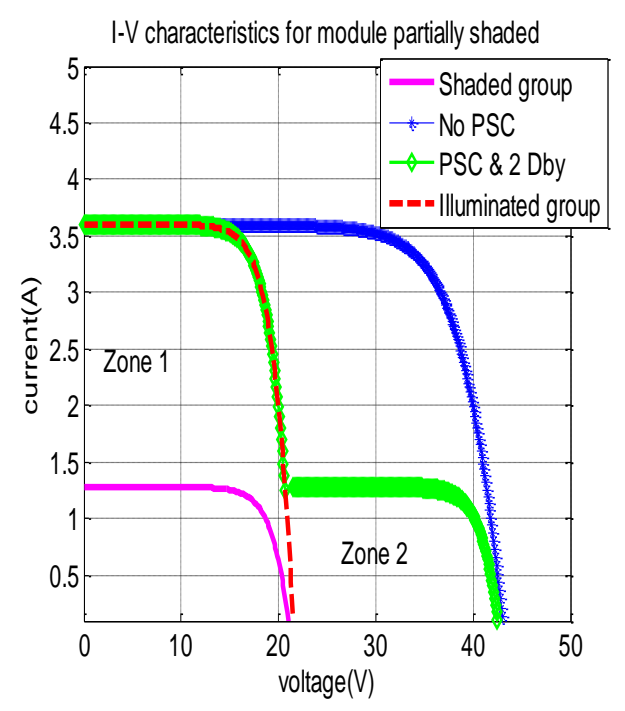

[a]

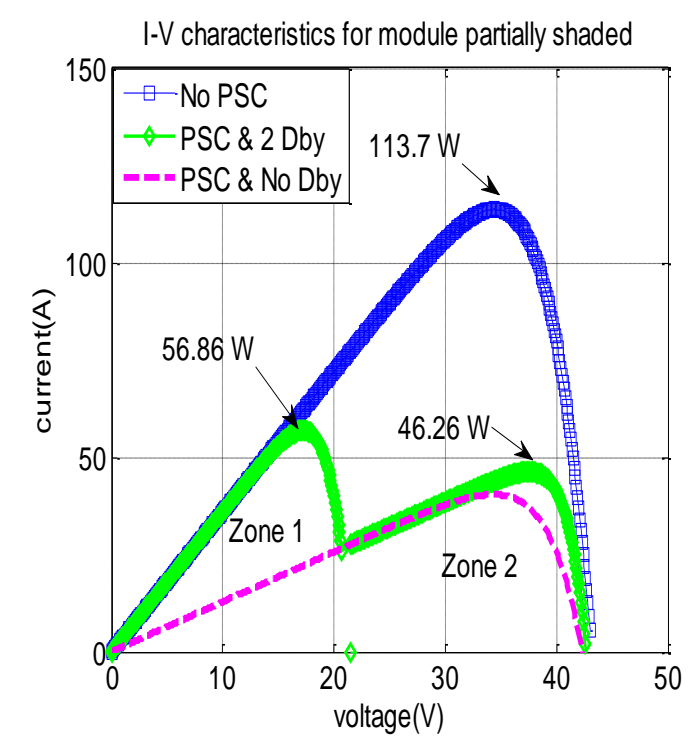

[b]

Fig.4 (a) I-V and (b) P-V c/cs of PV module with 2 Dby and one cell under PSC of $75 \%$.

From Fig.4 the maximum power from the module under PSC is $56.86 \mathrm{~W}$ where the half number of cells of the module was to produce about $56.85 \mathrm{~W}$ if they were fully illuminated. In the same manner, when integrating two bypass diodes in the module, the output power will be also $56.86 \mathrm{~W}$ and the power reduction is 50.01 $\%$, where with one bypass diode the output was $40.396 \mathrm{~W}$ and the power reduction is
$64.48 \%$. So the added bypass diode saves about $15 \%$ from losses.

The same is done for several shading ratios of one cell inside the module with two Dby and results are shown in Fig.5. a and b .Power reduction and $\mathrm{P}_{\max }$ also recorded in Table.2.

Table. 2 performance of one module at noon under $P S C \& 2 D b y$.

\begin{tabular}{|c|c|c|c|c|c|}
\hline $\begin{array}{c}\text { Shading } \\
\text { ratio \% }\end{array}$ & 0 & 25 & 50 & 75 & 100 \\
\hline $\begin{array}{c}\text { Maximum } \\
\text { power (W) }\end{array}$ & 113.7 & 89.3 & 64.81 & 56.83 & 56.83 \\
\hline $\begin{array}{c}\text { Power } \\
\text { reduction } \\
\%\end{array}$ & 0 & 21.5 & 43 & 50.02 & 50.02 \\
\hline
\end{tabular}

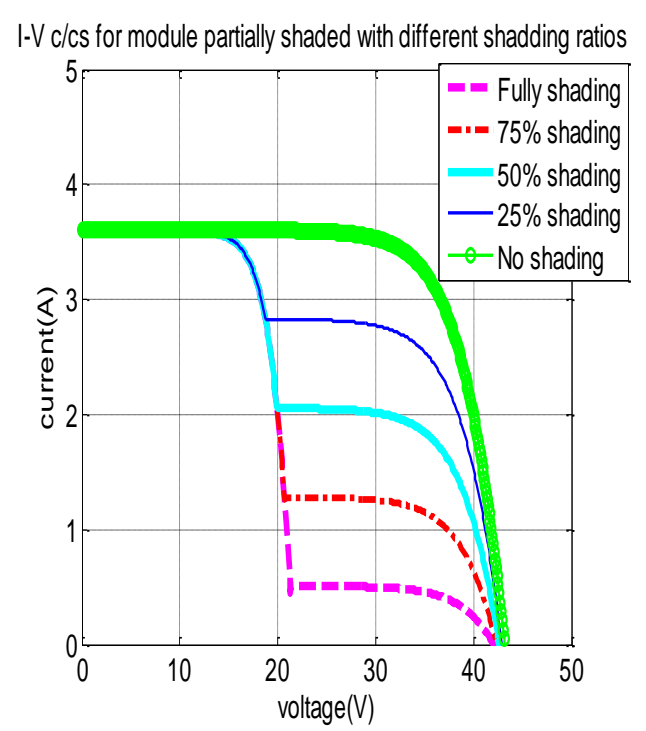

[a]

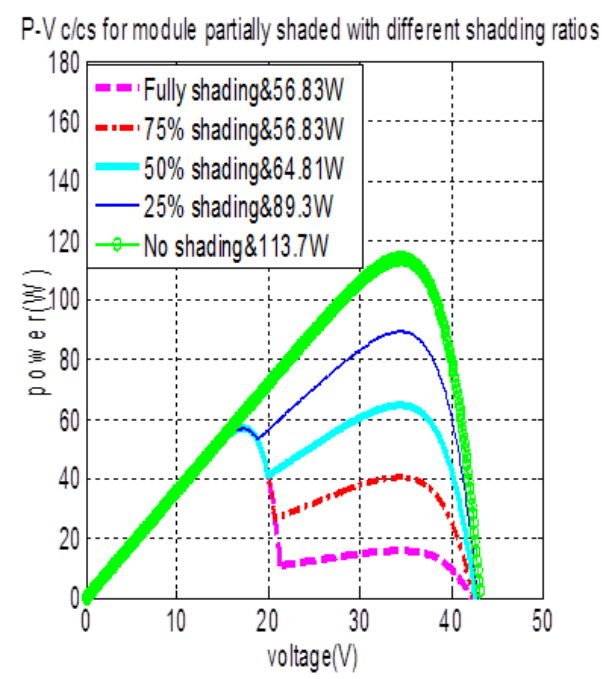

[b]

Fig.5 (a) I-V and (b) P-V c/cs of PV module with 2 Dby and one cell under different shading ratios. 
For one cell in a module shaded with $25 \%$ , $50 \%, 75 \%$ and $100 \%$ shading ratios the power losses are $21.5 \%, 43 \%$, $50.02 \%$ and $50.02 \%$ respectively, where the power reduction before inserting the second bypass diode for the same shading ratios was $21.5 \%, 43 \%$ and $64.4 \%$ and $86 \%$ respectively. The saving in losses due to for the same shading ratios was $0 \%$ $, 0 \%, 14 \%$ and $36 \%$ respectively.

From Tables 1 and 2, it is noted that the maximum power points of modules with 2 bypass diodes at shading ratios up to $50 \%$ and occurred before activating the $2^{\text {nd }}$ bypass diode. So it can be concluded that using only two bypass diodes for one module would not result in saving losses due to shading for shading ratios up to $50 \%$. It will be more effective for only shading ratios greater than $50 \%$.

\subsection{Effect of different numbers of Bypass diodes on PVG performance.}

When one cell in a module which is connected with different numbers of bypass diode is under PSC of different shading ratios the results are presented as following.

Table 3 performance of one module under PSC \& different number of Dby

\begin{tabular}{|c|c|c|c|c|c|}
\cline { 2 - 7 } \multicolumn{1}{c|}{} & \multicolumn{5}{c|}{ Power reduction (\%) } \\
\hline $\begin{array}{c}\text { Dby. } \\
\text { No } \\
\text { Sh }\end{array}$ & 0 & 2 & 3 & 4 & 9 \\
\hline $25 \%$ & 21.5 & 21.5 & 21.5 & 21.5 & 11.1 \\
\hline $50 \%$ & 43 & 43 & 33.3 & 25 & 11.1 \\
\hline $75 \%$ & 64.5 & 50.01 & 33.3 & 25 & 11.1 \\
\hline
\end{tabular}

According to results in Table3, it can be noted that:

For shading ratio of $25 \%$, No saving in losses will occur unless more than 4 diodes inserted over each module. For shading ratios equal to or higher than $50 \%$, inserting more than 2 diodes will reduce losses proportional to diodes number as expressed in equation 7 .

The power losses in module under PSC of one cell or (cells in one sub-module) with different numbers of bypass diodes expressed by the following expression:

$\mathrm{P}_{\text {loss }}(\mathrm{W})=\left(\frac{\text { Pmax at Sh } 0 \%}{\text { No.of Dby }}\right)$

\section{Different configurations of modules inside PV array}

The number of strings and the string length inside the array present different configurations of modules inside array as shown in Fig.6 as explained in the following section [8].

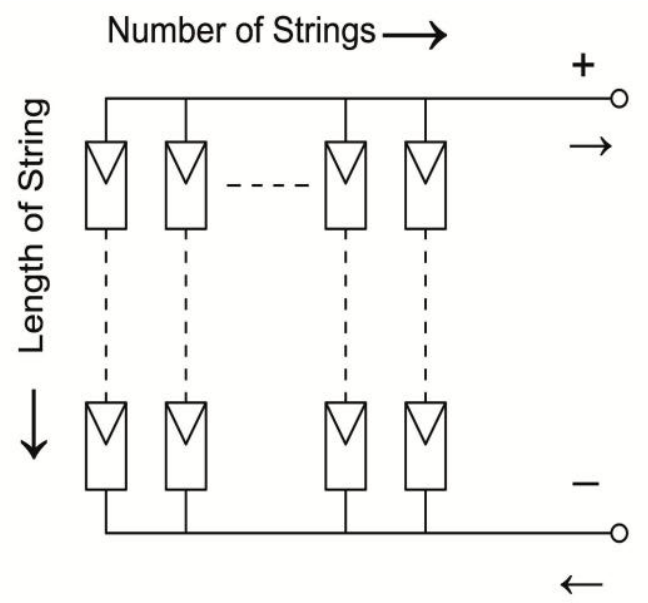

Fig.6 Configuration of modules inside array of $\boldsymbol{P V}$.

\subsection{Effect of length of string}

The theory explained in [13]-[14] to evaluate characteristics of an array of two series modules each with one Dby which is under PSC is expanded here to be applied on any length of strings and any number of Dby and sub-modules under PSC in an array is shown in Fig.7. As discussed before in explaining the characteristics of partially shaded module, the same idea is applied where the string is composed of several groups of sub-modules; each group receives the same irradiance level. 


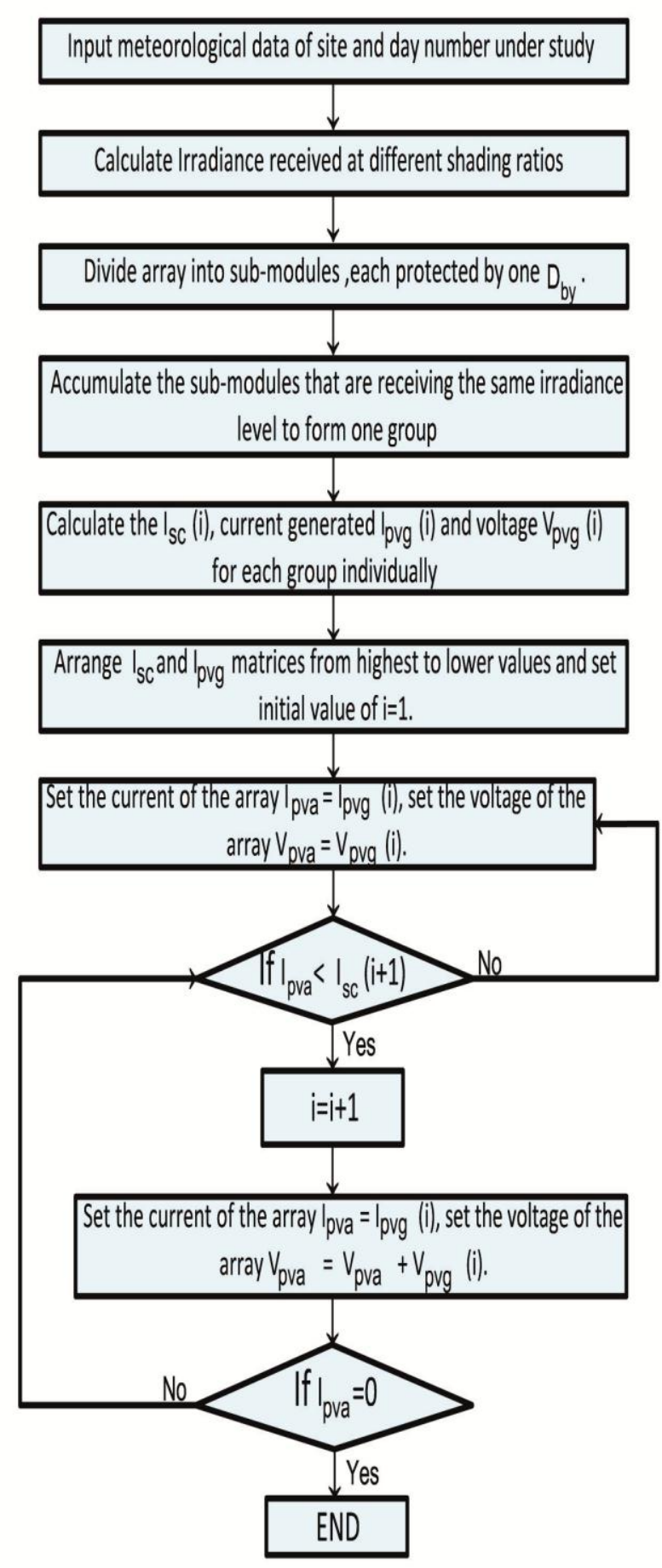

Fig.7 Algorithm of c/cs of one string array under PSC.

\subsubsection{Two modules in series with two bypass diodes over each module}

The P-V c/cs of two modules in series with two bypass diodes, and one cell in one module under different shading ratios is shown in Fig.8 according to algorithm in Fig.7 .

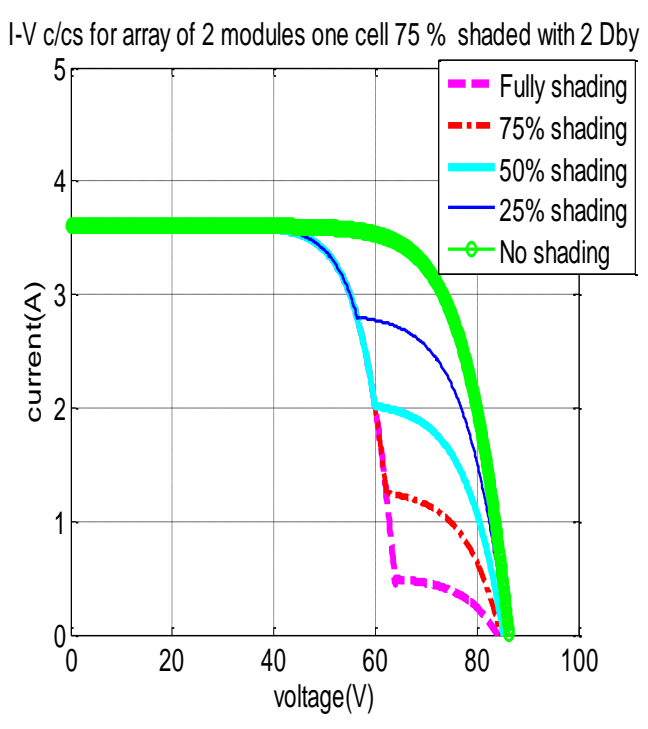

[a]

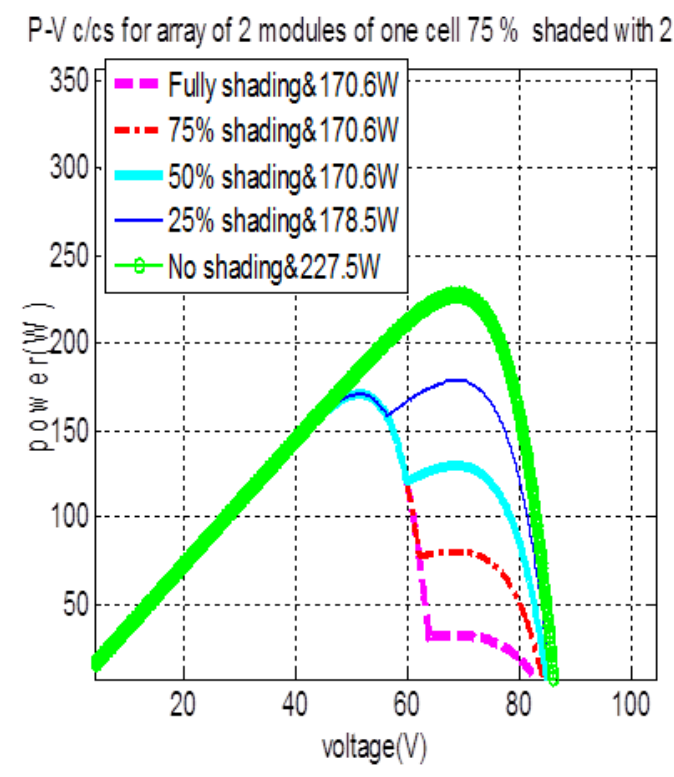

[b]

Fig.8 (a) I-V and (b)P-V c/cs of PV array with one cell under different values of sh \% and 2 of Dby over each module.

The same for three, six, ten, twenty and forty modules connected in series, the maximum power output is $284.3 \mathrm{~W}, 625.8$ $\mathrm{W}, 1080.5 \mathrm{~W}, 2217.8 \mathrm{~W}$ and $4492.4 \mathrm{~W}$ respectively. From these results, it can be concluded that for one string of series modules, when one cell only (or any number of cells in one sub-module) partially shaded, shading losses can be simplified to be calculated through the power of one sub-module which equal 56.8 
W. But the relative losses diminish when the string length increases. These results are shown in Fig.9

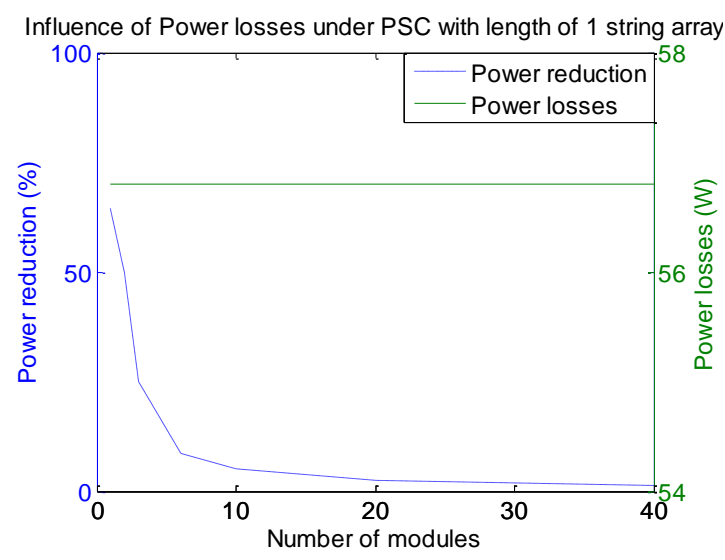

Fig.9 Power Loss and Power Reduction in One String Array of Different Lengths for One Cell under $75 \%$ PSC.

\subsubsection{Three modules in series with one bypass diode under different shading ratios of two modules}

For three modules M1, M2 and M3 connected in series, if M1 is fully illuminated. However, in M2 and M3 one cell in is subjected to partial shading of $50 \%$ and $75 \%$ respectively[2],[5].The $\mathrm{I}-\mathrm{V}$ and $\mathrm{P}-\mathrm{V}$ c/cs of the PS array is shown in Fig.10 a and b respectively .

As explained previously the current of the array will be the highest value of modules output, which is $\mathrm{I}_{\mathrm{M} 1}$, in this interval the other two modules are reverse biased and shorted by the bypass diode over each module. Till this the array c/cs will be the c/cs of M1.

When the M2 current $I_{M 2}$ is higher than $\mathrm{I}_{\mathrm{M} 1}, \mathrm{M} 2$ will be forward biased and still M3 reversed, the c/cs of the array in this stage will be as following M1 and M2 producing the voltage of the array and the current passing will be $\mathrm{I}_{\mathrm{M} 2}$. When the M3 current $\mathrm{I}_{\mathrm{M} 3}$ is higher than $\mathrm{I}_{\mathrm{M} 2}$, M3 will be forward biased and still M2 forward biased and, the c/cs of the array in this stage will be as if three series modules are uniformly illuminated with level of irradiance after $75 \%$ shading and current flowing through it is $\mathrm{I}_{\mathrm{M} 3}$.
The power output of the array after shading will be $126 \mathrm{~W}$. where before shading the output is $341.2 \mathrm{~W}$. This means that the power reduction is $63.1 \%$. Three shaded cells among 216 cells for the string only reduce the illuminated

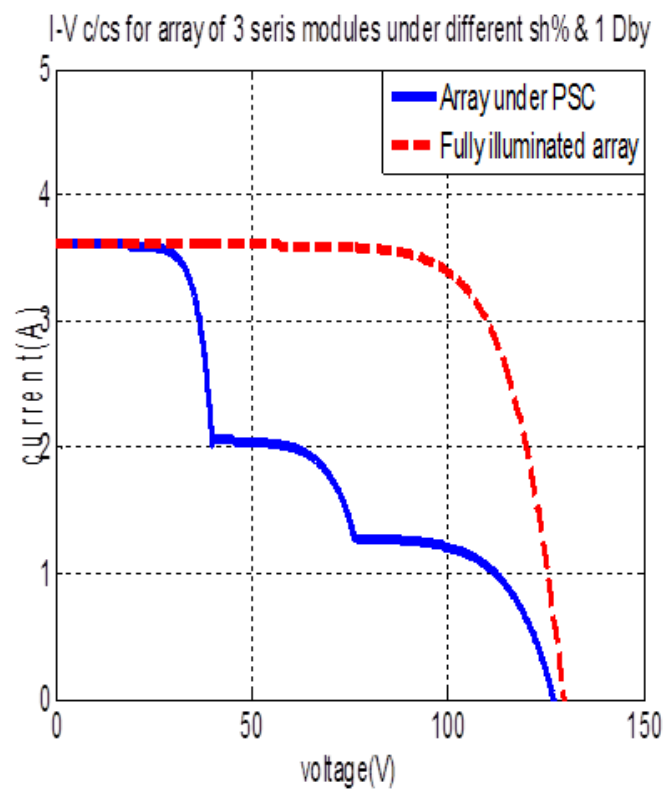

[a]

P-V c/cs for array of 3 seris modules under different sh $\%$ \& 1 Dby

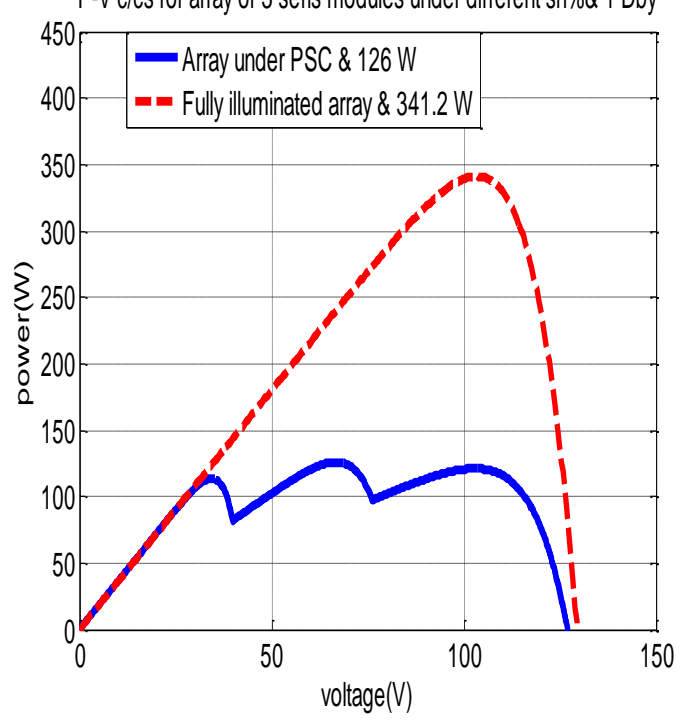

[b]

Fig.10 (a) I-V and (b) P-V c/cs of PV array with one Dby over module and 2 sub-modules under $50 \%$ and $75 \%$ shading ratios area by $1.38 \%$

When this simulation is repeated for the same conditions but with inserting 2Dby 
instead of 1Dby for each module, the power output was found $227.5 \mathrm{~W}$ which means that the power reduction is $33.32 \%$ only instead of $63.1 \%$. Also it is noted that the power losses in one string array under PSC, is not simply the power of submodules under PSC, but it depends on the number of sub-modules shaded, the shading ratio and number of bypass diodes over each module.

\subsection{Effect of number of strings in different $\mathrm{PV}$ array sizes on the shading losses (Parallel connection or several strings array)}

When strings contain modules under PSC are connected in parallel with another strings which uniformly illuminated,the output characteristics will be calculated for each string according to algorithm in Fig.7 Since the voltage is constant for strings connected in parallel, the total array current will be the sum of the currents passing through each cell operating at the same voltage. Two parallel strings of different string lengths will be explained in the following section.

\subsubsection{Two parallel strings each of two modules with two bypass diodes for each module}

When a module in which one cell is

PS with $75 \%$ connected in parallel with fully illuminated module the array $\mathrm{c} / \mathrm{cs}$ will be as shown in Fig.11 a and b.

Similar simulations were done to simulate performance of array of one string in which one cell under PSC $75 \%$ is connected in parallel with fully illuminated string; each string consists of ten, twenty and forty modules each connected with 2 bypass diodes.

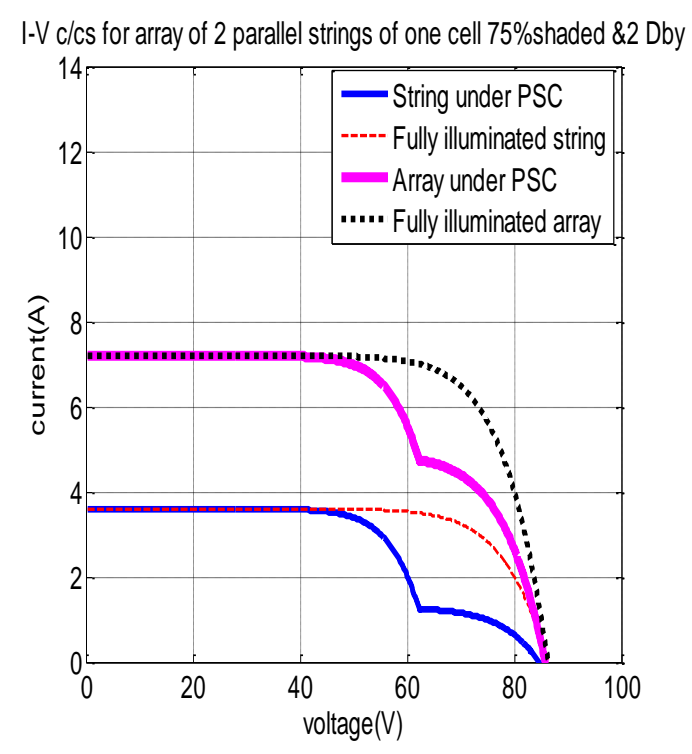

[a]

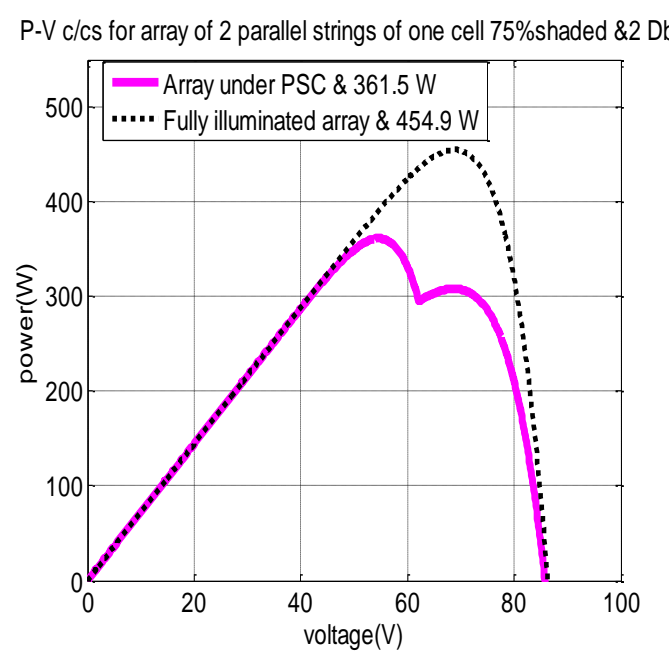

[b]

Fig.11 (a) I-V and (b) P-V c/cs of PV array of 2 strings in which one cell under 75\% PSC \& 2 Dby per module.

The simulation results show that the power reduction was, $20.5 \%, 12.5 \%, 5.5 \%, 2.9 \%$, $1.35 \%$ and $0.6 \%$ for strings of length $2,3,6,10,20$ and 40 modules, respectively.

This indicates that the power reduction becomes lower for long strings, and approximately diminishes for strings of 10 modules (Voltage of string $=340 \mathrm{v}$ ). This simulations were repeated for 3 parallel strings each string consists of 2,3,6,10,20 and 40 modules each connected with 2 bypass, the relative losses were 
$17.9 \%, 10.1 \%, 3.8 \%, 2 \%, 0.93 \%$ and $0.4 \%$ respectively. This indicates that increasing the PV array size makes it less sensitive to the PSC.

The results of simulations are recorded in tables $(4,5)$ and drawn in Fig12.

Table .4 Power reductions due to PSC in different array configurations and sizes with 2Dby over each module.

\begin{tabular}{|c|c|c|c|}
\hline Modules/string & $\begin{array}{c}\text { One } \\
\text { string }\end{array}$ & $\begin{array}{c}\text { Two } \\
\text { strings }\end{array}$ & $\begin{array}{c}\text { Three } \\
\text { strings }\end{array}$ \\
\hline 1 & 50 & 32.1 & 21.4 \\
\hline 2 & 24.96 & 20.5 & 18 \\
\hline 3 & 16.65 & 12.4 & 10.1 \\
\hline 6 & 8.3 & 5.3 & 3.9 \\
\hline 10 & 5 & 3 & 2.1 \\
\hline 20 & 2.5 & 1.35 & .92 \\
\hline 40 & 1.25 & .65 & .44 \\
\hline
\end{tabular}

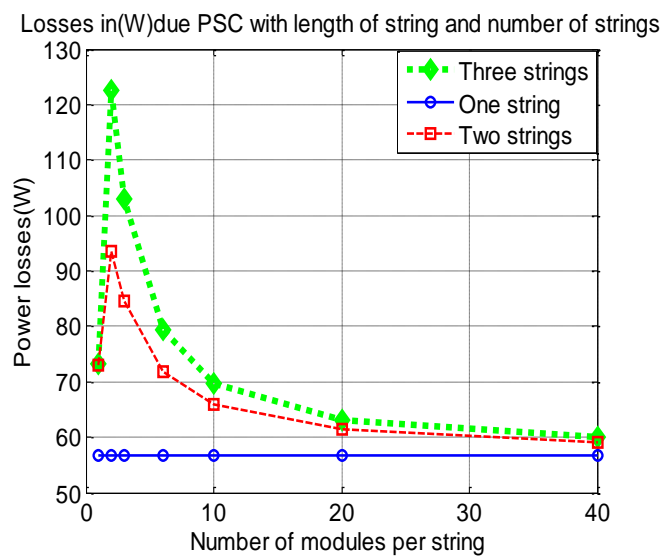

[a]

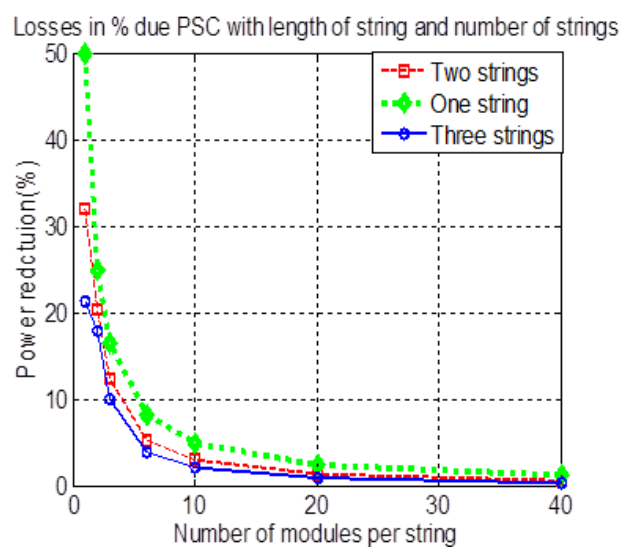

[b]

Fig.12 (a)power losses in (W) and (b) power reduction in (\%) due to 75\% PSC in one cell in an array of diferent configurations.
From results recorded in table 4 and drawn in Fig.12, it is noted that when several strings are in parallel, the maximum power decreased more and causing additional losses in the other strings production, but for long strings this effect vanishes for strings of more than 10 modules per string. Table .5 Comparisons between power reductions due to PSC in different array configurations in the same array size with 2Dby over each module.

\begin{tabular}{|c|c|c|c|}
\cline { 2 - 4 } \multicolumn{1}{c|}{} & \multicolumn{3}{c|}{ Power reduction (\%) } \\
\hline $\begin{array}{c}\text { Number of } \\
\text { modules in } \\
\text { the array }\end{array}$ & $\begin{array}{c}\text { One } \\
\text { string }\end{array}$ & $\begin{array}{c}\text { Two } \\
\text { strings }\end{array}$ & $\begin{array}{c}\text { Three } \\
\text { strings }\end{array}$ \\
\hline 2 & 24.96 & 32.1 & - \\
\hline 3 & 16.65 & - & 21.4 \\
\hline 6 & 8.3 & 12.4 & 18 \\
\hline 20 & 2.5 & 3 & - \\
\hline 40 & 1.25 & 1.35 & - \\
\hline
\end{tabular}

From results in Table.5, it is noted that increasing the number of strings in the same array size reduces the performance of the array severely. As introduced by several authors, in Dynamic Array Reconfiguration method [1], [16], where the reconfiguration implemented to increase the array degree of parallelism to reduce the shadow effects. It is unexpected result that only one string array behaves much better than arrays of several strings and this is for shading ratios larger than $50 \%$.

From simulations for arrays under partial shading modules with different interconnections between modules and numbers of bypass diodes, it is shown that the losses due to shading can be decreased with increasing number of bypass diodes to block only small number of cells when shading occur. But this is not practical solution, since it adds non linearity for the PV system which leads to mismatching between diodes and also there will be losses in the bypass diodes itself. So the proposed compensation algorithm for adjusting the array declination continuously to prevent shadowing from mutual shading between modules will be implemented in the following section to 
examine its ability in increasing efficiency of PV systems under partial shading condition .

\section{Shadow length compensation algorithm implementation}

In this method the inclination angle of the PV system is changed by altitude angle of sun. Consequently, a length of shadow is changed by variation of the inclination angle [13],[18].

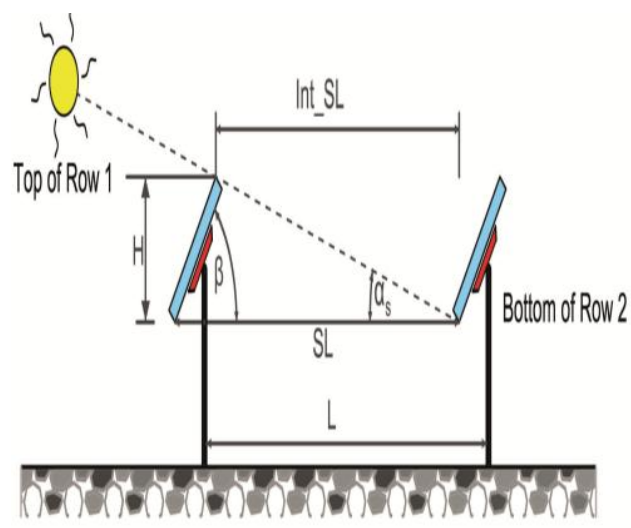

Fig.13 shows shadow length computation of $P V$ array by altitude.

The algorithm of this method is given in Fig.14.

It calculates the distance between arrays by using the azimuth of solar $\gamma_{s}$, and length of array shadow SL which is calculated by using the altitude of solar $\alpha s$ and declination angle $\beta$ of PV array. The shadow compensation algorithm proposed compares distance between arrays and length of array shadow. When the shadow length is longer than the distance between arrays, the algorithm adjusts tilt angle of the array to avoid the shadow effects.

From Fig.13 the shadow length will be calculated as follow:

$\mathrm{SL}=$ Int_SL + W

$\mathrm{W}=\mathrm{AL} \cdot \cos (\beta)$

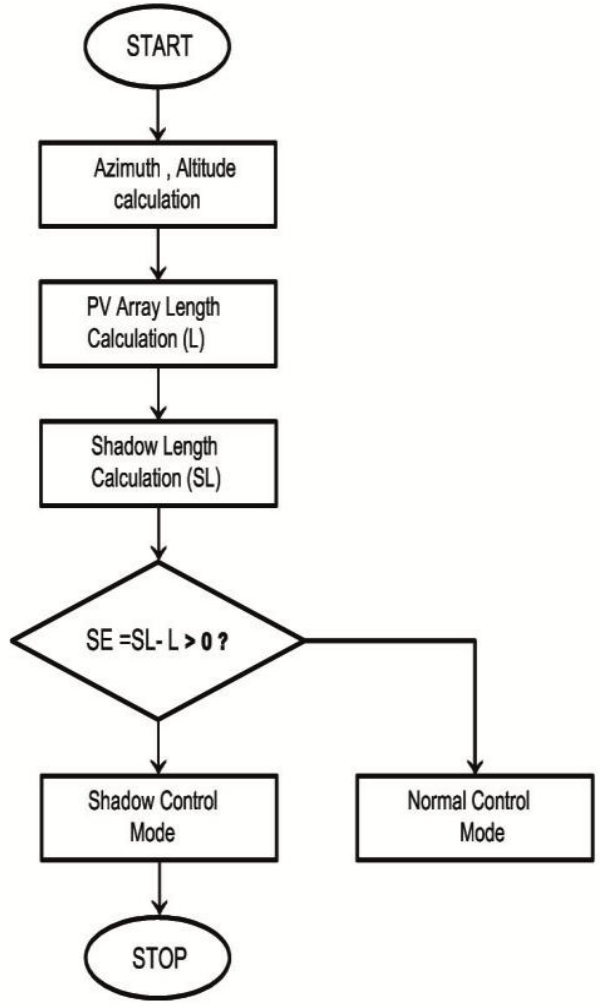

Fig.14 the new control algorithm considering shadow effects.

AL:is the array length (mm).

Int_SL $=\mathrm{H} / \tan \left(\alpha_{\mathrm{s}}\right)$

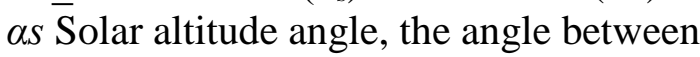
the horizontal and the line to the sun, that is, the complement of the zenith angle $\left({ }^{\circ}\right)[19]$.

$\alpha_{\mathrm{s}}=\sin ^{-1}[\cos \varphi \cos \delta \cos \omega+\sin \varphi \sin \delta$ ]. (11)

Where, $\varphi$ Latitude, the angular location north or south of the equator, north positive; $-90^{\circ} \leq \varphi \leq 90^{\circ}$.

$\delta$ Declination, the angular position of the sun at solar noon (i.e., when the sun is on the local meridian) with respect to the plane of the equator, north positive; $-23.45^{\circ} \leq \delta \leq 23.45^{\circ}$.

$\delta=23.45 \sin \left(\frac{360(284+n)}{365}\right)$

$n$ : is the day number in the year.

$\omega$ Hour angle, the angular displacement of the sun east or west of the local meridian due to rotation of the earth on its axis at $15^{\circ}$ per hour; morning negative, afternoon positive $\left({ }^{\circ}\right)$.

$\omega=(t-12) \times 15$ 
$\mathrm{H}=\mathrm{AL} \cdot \sin (\beta)$.

\subsection{Distance between arrays calculation $\mathbf{L}$ \\ $\mathrm{L}=\mathrm{C} \times \cos (\theta)$

Where,

$\mathrm{C}$, is an array size constant, $\theta$ is calculated from azimuth angle through the set of equations (7-22) in [13].

$\gamma_{s}$ Solar azimuth angle, the angular displacement from south of the projection of beam radiation on the horizontal plane.

$\gamma_{s}=\operatorname{sign}(\omega)\left|\cos ^{-1}\left(\frac{\cos \theta_{z} \sin \phi-\sin \delta}{\sin \theta_{z} \cos \phi}\right)\right|(16)$

Compensating shadow length

The difference between $\mathrm{L}$ and SL is expressed as SE and calculated as following:
$\mathrm{SE}=\mathrm{SL}-\mathrm{L}$

The compensation angle is as follows

$\mathrm{M} \theta=\cos ^{-1}\left(\frac{L}{S L}\right)$

The declination angle of the array will be modified to compensate the shadow influence and will be as follows:

$\mathrm{M} \beta$ (Modify tilt angle) $=\alpha_{\mathrm{s}}+\mathrm{M} \theta$ (19)

So For a considered day assume 17 Jan, for Al_ Arish city for that day and for a PV module settled on an inclination angle (tilt angle) which is chosen to be constant equal Latitude - declination, which equal 51.987. The results from applying shadow compensation algorithm is shown in Table. 6

Table .6 Implementation of SLCA for $17^{\text {th }}$ January for Al-Arish city.

\begin{tabular}{|c|c|c|c|c|c|c|c|c|}
\hline $\begin{array}{c}\text { Day } \\
\text { time } \\
\text { (hours) }\end{array}$ & $\begin{array}{l}\text { Azimuth } \\
\text { angle }\left(^{0}\right)\end{array}$ & $\begin{array}{c}\text { Solar } \\
\text { altitude } \\
\text { angle }\left({ }^{0}\right)\end{array}$ & $\begin{array}{c}\text { Array } \\
\text { distance } \\
\mathbf{L}(\mathbf{m m})\end{array}$ & $\begin{array}{c}\text { Tilt } \\
\text { angle( }\left(^{0}\right)\end{array}$ & $\begin{array}{c}\text { Shadow } \\
\text { length }(\mathrm{mm})\end{array}$ & $\begin{array}{c}\text { SE } \\
(\mathbf{m m})\end{array}$ & $\begin{array}{c}\text { Compensati } \\
\text { on angle }\left({ }^{0}\right)\end{array}$ & $\begin{array}{c}\text { Modifie } \\
\text { d Tilt } \\
\text { angle }\left(^{0}\right)\end{array}$ \\
\hline 7 & 64.4894 & 1.3081 & 8918.0 & 51.987 & 166110 & 157190 & 86.9225 & 88.2306 \\
\hline 8 & 55.9422 & 12.4622 & 9288.0 & 51.987 & 19780 & 10490 & 61.9867 & 74.4489 \\
\hline 9 & 45.6063 & 22.4266 & 9459.5 & 51.987 & 11940 & 2480 & 37.6193 & 60.0459 \\
\hline 10 & 32.8517 & 30.5739 & 9248.2 & 51.987 & 9220 & -30 & $\mathbf{0}$ & 30.5739 \\
\hline 11 & 17.4004 & 36.0562 & 8383.5 & 51.987 & 8030 & -350 & 0 & 36.0562 \\
\hline 12 & $\mathbf{0}$ & 38.0130 & 6689.2 & 51.987 & 7680 & 990 & 29.4331 & 67.4461 \\
\hline 13 & 17.4004 & 36.0562 & 8383.5 & 51.987 & 8030 & -350 & 0 & 36.0562 \\
\hline 14 & 32.8517 & 30.5739 & 9248.2 & 51.987 & 9220 & -30 & $\mathbf{0}$ & 30.5739 \\
\hline 15 & 45.6063 & 22.4266 & 9459.5 & $\mathbf{5 1 . 9 8 7}$ & 11940 & 2480 & 37.6193 & 60.0459 \\
\hline 16 & 55.9422 & 12.4622 & 9288.0 & 51.987 & 19780 & 10490 & 61.9867 & 74.4489 \\
\hline 17 & 64.4894 & 1.3081 & 8918.0 & 51.987 & 166110 & 157190 & 86.9225 & 88.2306 \\
\hline
\end{tabular}


After calculating the modified tilt angle through the compensation algorithm and then the performance of the PV array will be calculated through

- $\quad$ Calculating the irradiance received by the PV array at the new inclination

- $\quad$ Calculating the performance of PV array at the new inclination angle and comparing results with the output when using two bypass diodes over one module .

- The results from MATLAB simulation is drawn in the Fig.15 and table.7.

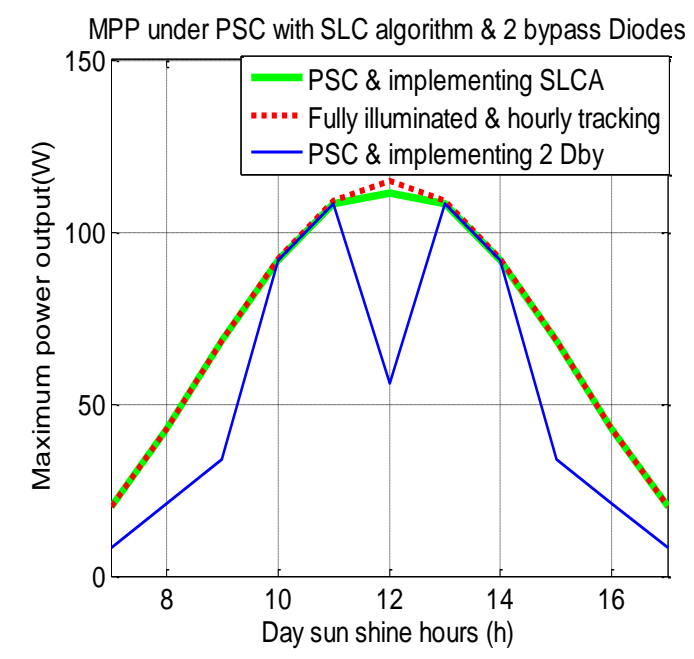

Fig.15 $P_{\max }$ from one module under PSC using SLCA and $2 D_{b y}$.

Table. 7 performance of one module under PSC \& different solutions.

\begin{tabular}{|c|c|c|c|c|}
\cline { 2 - 6 } \multicolumn{1}{c|}{} & \multicolumn{4}{c|}{ Maximum power output along day } \\
\multicolumn{4}{c|}{ hours (W) } \\
\hline $\begin{array}{c}\text { Day } \\
\text { hours }\end{array}$ & $\begin{array}{c}\text { Daily } \\
\text { tracking }\end{array}$ & $\begin{array}{c}\text { Hourly } \\
\text { tracking }\end{array}$ & $\begin{array}{c}\text { PSC\& } \\
\text { SLCA }\end{array}$ & $\begin{array}{c}\text { PSC } \\
\text { \& } \\
\text { 2Dby }\end{array}$ \\
\hline 7 & $\mathbf{1 6 . 5 9 9 7}$ & $\mathbf{2 0 . 0 4 5 4}$ & $\mathbf{2 0 . 0 4}$ & $\mathbf{8}$ \\
\hline $\mathbf{8}$ & $\mathbf{4 1 . 3 9 1}$ & $\mathbf{4 2 . 6 7 8}$ & $\mathbf{4 2 . 4 6}$ & $\mathbf{2 1}$ \\
\hline 9 & $\mathbf{6 7 . 9 2 1 9}$ & $\mathbf{6 8 . 5 2 1}$ & $\mathbf{6 8 . 5 1}$ & $\mathbf{3 4}$ \\
\hline 10 & $\mathbf{9 1 . 5 7 0}$ & $\mathbf{9 2 . 2 9 9}$ & $\mathbf{9 1 . 5 7}$ & $\mathbf{9 1 . 6}$ \\
\hline 11 & $\mathbf{1 0 7 . 9 0}$ & $\mathbf{1 0 8 . 9 8}$ & $\mathbf{1 0 7 . 9}$ & $\mathbf{1 0 8}$ \\
\hline 12 & 113.73 & $\mathbf{1 1 4 . 9 8}$ & $\mathbf{1 1 1 . 4 6}$ & $\mathbf{5 6}$ \\
\hline 13 & $\mathbf{1 0 7 . 9 0}$ & $\mathbf{1 0 8 . 9 8}$ & $\mathbf{1 0 7 . 9}$ & $\mathbf{1 0 8}$ \\
\hline 14 & $\mathbf{9 1 . 5 7 0}$ & $\mathbf{9 2 . 2 9 9}$ & $\mathbf{9 1 . 5 7}$ & $\mathbf{9 1 . 6}$ \\
\hline 15 & $\mathbf{6 7 . 9 2 2}$ & $\mathbf{6 8 . 5 2 1}$ & $\mathbf{6 8 . 5 1}$ & $\mathbf{3 4}$ \\
\hline 16 & $\mathbf{4 1 . 3 9 1}$ & $\mathbf{4 2 . 6 7 8}$ & $\mathbf{4 2 . 4 6}$ & $\mathbf{2 1}$ \\
\hline 17 & $\mathbf{1 6 . 5 9 9}$ & $\mathbf{2 0 . 0 4 5}$ & $\mathbf{2 0 . 0 4}$ & $\mathbf{8}$ \\
\hline $\begin{array}{c}\text { Daily } \\
\text { energy } \\
\text { w/day }\end{array}$ & $\mathbf{7 6 4 . 5}$ & $\mathbf{7 8 0 . 0 4}$ & $\mathbf{7 7 2 . 8}$ & $\mathbf{5 8 1 . 2}$ \\
\hline
\end{tabular}

The results shown in Fig.15 and table 7 show that when using shadow compensation algorithms, the shadow effect by modules to each other vanishes. And power reduction with respect to the hourly inclination in the case of using 2 bypass diodes and compensation algorithm is $25.5 \%$ and $1.1 \%$ respectively when shading in one sub-module occur.This is an indicator that this method is effective and saves losses more than bypass diodes ,in case of shading by modules on each other. But when considering shading by other factors like birds or clouds the simulation results shows that for one string array, two bypass diodes will save losses to a great extent for long strings.

\section{Conclusion}

This paper presented a simplified methodology which accurately determines the characteristics of PV array under PSC. The results were simulated by Matlabsimulation programming. Simulation results show that the power reduction due to PSC depends on the size of the array, since it is lower in the case of large scale arrays. Also this reduction depends on; the number of sub-modules under PSC, the configuration of modules inside the array and the number of Dby connected across each module. Simulation results show the severe reduction in the performance of the PV systems which have several strings in parallel rather than one array string for the same PSC state. When PSC occurred in more than one sub-module in PV array, the power reduction compounded and increased to be more than rejecting the power produced by these sub-modules. Doubling the number of Dby can approximately doubles the power produced and this will reduce the effect of PSC but only for low shading ratios. Also the implementation of SLCA for PV array under mutual PSC were compared with implementing 2 Dby and found to have better performance under mutual PSC. But when considering shading by clouds or any subject, integrating 2 Dby is integrated to 
prevent the damage of PV module due to hot spot phenomena. This research will help PV system designers to optimize their designs of PV system under PSC.

\section{References}

[1] Mohamed.Mamdouh,PhD of Faculty of engineering , Cairo university,2004,"Fault Detection Of $\mathrm{Pv}$ System Using Advanced Simulation".

[2] J. Guerrero1, Y Muñoz2," Analysis of mismatch and shading effects in a photovoltaic array using different technologies" IOP Conf. Series: Materials Science and Engineering 59 (2014) 012007 doi:10.1088/1757899X/59/1/012007.

[3] Hongmei Tian " A cell-to-moduleto-array detailed model for photovoltaic panels"'a,Solar Energy 86 (2012) 2695-2706

[4] M. Chegaar1*,' Effect of illumination intensity on solar cells parameters" Terra Green 13 International Conference 2013 Advancements in Renewable Energy and Clean Environment.

[5] André Mermoud, Thibault Lejeune" PARTIAL SHADINGS ON PV ARRAYS: BY-PASS DIODE BENEFITS ANALYSIS", Institute for the Sciences of Environment / Group of Energy, University of Geneva,In: 25th European Photovoltaic Solar Energy Conference, 2010.

[6] G. Shankar, V. Mukherjee," MPP detection of a partially shaded PV array by continuous GA and hybrid PSO", Ain Shams Engineering Journal, 2014.

[7] B.Paranthagan1," Global Maximum Power Point Tracking Under Partial Shading Condition Using SEPIC Converter", International Journal of Advanced Research in Electrical, Electronics and Instrumentation Engineering, Vol. 4, Issue 2, February 2015.
[8] Brian Goss, Ian Cole," Irradiance modelling for individual cells of shaded solar photovoltaic arrays", Solar Energy 110 (2014) 410-419.

[9] Chris Deline a, " A simplified model of uniform shading in large photovoltaic arrays" ,Solar EnergyVolume 96, October 2013, Pages 274-282.

[10] L. Fialhoa,c, R. Melicioa,c," Effect of Shading on Series Solar Modules: Simulation and Experimental Results", Procedia Technology 17 ( 2014 ) 295 - 302, Conference on Electronics, Telecommunications and Computers - CETC 2013.

[11] F. Martinez-Moreno * J. Muñoz, E. Lorenzo," Experimental model to estimate shading losses on PV arrays",Instituto de Energia SolarUniversidad Politecnica de Madrid(IES-UPM),2010.

[12] O.Perpinan," Cost of energy and mutual shadows in two-axis tracking PV system", renewable energy, 2012.

[13] Jae-Sub Ko* and Dong-Hwa Chung, "Control of a Novel PV Tracking System Considering the Shadow Influence.", Journal of Electrical Engineering \& Technology,2012.

[14] Mohammad mehdi Seyed mahmoudian1," Analytical Modeling of Partially Shaded Photovoltaic Systems", energies, 2013.

[15] Zhou Diqing,"Modeling and simulation of partial shaded PV modules",T.Xiao:ICSC 2012,Part II,CCIS 327,PP.124-134,2012.

[16] Tony Maine* a and John Bellb," Maximum Power Extraction from Partially Shaded PV Arrays" In Prasad, D \& Morrison, $G$ (Eds.) Proceedings of the 3rd International Solar Energy Society Conference, Asia Pacific Region, incorporating the 46th Australian New Zealand Solar Energy Society Conference (ISES-AP-08), 25 - 28 November, 2008, Australia, NSW, Sydney. 
[17] M.Drif,P.J.Perez,"A new estimation method of irradiance on a partially shaded pv generator in grid connected photovoltaic systems", Renewable Energy, 2008. "Calculating Inter-Row Spacing", SOLARPRO, 2009.

[18] John A. Duffie (Deceased), William A. Beckman," Solar Engineering of Thermal Processes Fourth Edition",Solar Energy Laboratory University of Wisconsin-Madison, 2005.

[19] Sahar.S.Kaddah,Mansoura university, "Genetic Algorithm based optimal operation for photovoltaic systems under different fault criteria" Power Systems Conference, 2006. MEPCON 2006. Eleventh International Middle East (Volume: 2). 